\title{
A presunção constitucional de inocência
}

\author{
Luiz Alberto Machado*
}

Sumário: Introdução; 1 . O princípio da certeza jurídica; 2. Uma visão de Estado.

\section{Introdução}

É declaração velha, da Revolução Francesa, que todo acusado beneficia-se da presunção de inocência; isto é, submetido a um processo legal devida e adredemente estabelecido, que atenda aos princípios básicos do contraditório e da ampla defesa (além de outros mais, tão ou menos votados), o due process of law tão citado e tão maltratado, o acusado é culpado apenas e tão somente após o trânsito em julgado da sentença criminal condenatória, nos exatos limites desta; até então, até a condenação trânsita em julgado, a presunção de inocência se embaralha e se apoia no princípio processual criminal do in dubio pro reo: a prova não definitiva ou duvidosa trabalha em favor do acusado. Esse princípio, considerado meta-constitucional por Colliard, foi adotado pela Carta da ONU - Organização das Nações Unidas e tardiamente recepcionado pela Constituição Federal brasileira em vigor, no art. $5^{\circ}$, inciso LVII ${ }^{1}$ não sem antes juristas ilustres como os Ministros Leitão de Abreu e Xavier de Albuquerque o haverem adotado em decisões memoráveis quando membros do Tribunal Superior Eleitora.

Embora isso, o processo criminal, no Brasil, impõe duas condenações preliminares, apressadas e absolutamente inconstitucionais, por serem préprocessuais: a primeira, ditada pela polícia judiciária na feitura do inquérito - procedimento ora importante, ora descartável, para fundamentar a denúncia ou a queixa-crime - quando indicia (ato inexistente no mundo jurídico

* Professor Titular do Departamento de Direito Penal e Processual Penal da Faculdade de Direito - UFPR.

1 "Ninguém será considerado culpado até o trânsito em julgado de sentença penal condenatória".

R. Fac. Direito. Curitiba, a.27, n.27, 1992/93. p.37-60 
mas praticado à larga pela polícia e admitido, por omissão e cumplicidade, pelo Ministério Público e pelo Poder Judiciário; a indiciação, assim como vem sendo vista e utilizada pela polícia e pelo Minis-tério Público, não existe; segundo o Aurélio, indiciar significa submeter a inquérito policial; vale dizer, indiciado é aquele que está sofrendo a investigação decorrente do inquérito policial; não há um ato de indiciação; havia, sim, o ato de identificação criminal, tornado inconstitucional pelo art. $5^{\circ}$, inciso LVIII, da Constituição Federal; portanto, não há esse ato formal, brutal, condenatório de indiciar; sabendo-se, porque identificado civilmente, quem é o autor do crime, o indiciado, nem a identificação criminal poderá ser efetuada); a segunda, quando os Parquets federal ou estadual, pouco importa - que atuam sobrepondo-se em atribuições e as confundindo -, denunciam o indiciado: o Ministério Público, de posse das informações contidas no inquérito policial, também sentencia, denunciando. Feito o que, o processo pára ou anda a passos de cágado. O status poenalis, que deveria ser um efeito secundário da sentença criminal condenatória, se estabelece com essas providências administrativas: a indiciação e a denúncia. A condenação constitucional, a ser proferida pelo órgão judiciário (jurisdição, jurisdictio, o poder de dizer definitivamente o direi-to, como ensinava Frederico Marques) se eterniza, ou jamais ocorrendo ou não sendo difundida quando absolutória; basta, à sanha da turba que condena antes de julgar, as duas condenações irregulares e inconstitucionais, esquecida de que o direito criminal é, antes e acima de tudo, o regulamentador do monopólio da força do Estado, como ensina Bobbio: a sociedade, ao sair do Estado de natureza (em que tudo é permitido) para o Estado de direito (em que alguma coisa é proibida) em antagonismo ao Estado ditatorial (em que alguma coisa é permitida), se institucionaliza pela força; mas, ao se organizar politicamente -

"O poder político pertence à categoria do poder de um homem sobre outro homem, mas não à categoria do poder do homem sobre a natureza." 2

-, a sociedade deve, ao mesmo tempo em que mantém o monopólio da força -

"Este processo de monopolização caminha pari passu com o processo de criminalidade e de penalização de todos os atos de violência que

2 Norberto Bobbio, O significado clássico e modemo de política, p. 12 
não sejam realizados por pessoas autorizadas pelos detentores e beneficiários deste monopólio." ${ }^{3}$

Regulamentar a sua utilização:

"Por Estado se deve entender uma empresa institucional de caráter político, na qual - e na medida em que - o aparelho administrativo consegue monopolizar a coerção física legítima." 4

Eu vejo o direito criminal dando vida ao controle constitucional do monopólio da força do Estado; como o direito constitucional brasileiro, no que tange com as realidades do respeito aos direitos e garantias individuais, está em crise - vejam-se os cínicos desrespeitos do Governo à Constituição Federal e ao seu guardião, o Supremo Tribunal Federal, com o presidente da República cometendo crimes de responsabilidade e arvorando-se, contra a Constituição, guaridão desta, sob o aplauso irresponsável de parte da mídia e dos políticos -, essa crise que atormenta, minimiza e desmoraliza o direito criminal se inicia na formulação dos crimes, adentra a doutrina, passa pela jurisprudência e, ao fim e ao cabo, atinge o homem. Já fui alertado pelo Rolf Koerner Junior e pelo Jacinto Coutinho, que me cometeram uma responsabilidade, que a linguagem do direito criminal está velha, caduca.

Quando as condenações são pronunciadas pelo delegado da polícia judiciária na indiciação, ou pelo Ministério Público, na denúncia, e assim se tornam públicas, quando as pessoas, comuns ou autoridades, são submetidas à pressa de um linchamento moral, quando o início da investigação se transforma no fim de um processo criminal que sequer se iniciou, o direito criminal vai à bancarrota, arrastando consigo todos os direitos individuais e tornando mortas as garantias constitucionais; quando juízes e promotores falam e usam o in dubio pro societate, o direito criminal se torna pré-jurássico; é a exumação da Constitutio Criminalis Carolina, a obra mais representativa do direito criminal bárbaro, medieval, com o séquito de ordálias e julgamentos divinos. Cappelletti alertou que a ofensa a um direito individual é a ofensa ao direito da coletividade. O exemplo do linchamento moral feito, de forma apressada e afastada dos mais comezinhos e elementares princípios do direito processual criminal, no caso do chamado jogo do

3 Norberto Bobbio, O significado clássico e moderno de política, p. 12.

4 Max Weber, Economia e società, Milano, 1961, v. I, p. 53.

R. Fac. Direito. Curitiba, a.27. n.27. 1992/93, p.37-60 
bicho, pelo Ministério Público estadual do Rio de Janeiro, com o aplauso irresponsável, até pela ignorância, da mídia, é a submissão dos direitos individuais constitucionais, expressos no direito criminal, à sanha dos ingênuos, de um lado, e dos politicamente engajados, de outro: o jogo do bicho foi tornado lícito pela ganância da administração pública na exploração de diversos jogos de azar, na permissão de que particulares os explorem, inclusive na televisão, e na ausência da consciência coletiva da sua tipicidade; ao contrário, o administrado vê o jogo do bicho como conduta dentro da normalidade social; não há o potencial conhecimento do ilícito, se se imaginasse que a conduta ainda fosse ilícita, e não o é; o costume a tornou atípica.

O Parquet federal, que eterniza as suas intervenções processuais, apressa-se em tutelar o povo, propondo, rapidamente, ação de extinção de mandato outorgado pelo povo; é o recall acusatório, onde se diz, sem palavras, que o povo não sabe votar e precisa desses sábios para corrigir as suas peraltices eleitorais; o estadual abre um cofre e corre à imprensa e televisão dizer que enfim, temos as provas que incriminam todos os nossos desafetos, queremos dizer, as autoridades públicas do Rio de Janeiro e alhures; toma disquetes de computador e os guarda sem qualquer participação dos apressadamente acusados, num retorno ao processo criminal secreto da santa inquisição: onde a garantia da dialética e disponibilidade e contraditoriedade e etc. das provas? Não; é o máu exemplo do Ministério Público italiano, falso herói da moralidade capaz de destruir a unidade da Itália doloridamente conquistada, em arremedos de processos modernos e contraditórios, que lá é chamado de judice e aqui de procurador ou promotor, que prende e arrebenta e impõe, de forma indireta, pela indução ao suicídio, a, também ali, inconstitucional pena de morte, sem qualquer prova, até hoje sem qualquer condenação: ninguém foi condenado, nenhum mandato foi cassado; a condenação de uns poucos mafiosos decorreu do arreglo imoral com os pentiti, tão criminosos quanto, mas perdoados pelos auto-investidos semi-deuses, numa cópia canhestra e borrada da plea bargain; é o avesso do processo criminal correto, democrático, contraditório, dialético; é o processo criminal da preguiça: acuse-se, porque com isso e só com isso se alcança a condenação, e a instrução probatória dialética, contraditória, disponivel, sob a presidência de um juiz imparcial, torna-se dispensável porque séria e trabalhosa. O Poder Judiciário, não o Ministério Público, tem o poder constitucional de dizer definitivamente o direito; o Poder Judiciário, não o Ministério Público, exerce o poder moderador da teoria constitucional 
americana, tão repetida ainda que incompreendida, dos checks and balances.

\section{O princípio da certeza jurídica}

Todo o mundo jurídico democrático, principalmente o criminal, deve assentar-se no princípio da certeza jurídica, que dá vida ao princípio constitucional da igualdade (ou isonomia) jurídica: este nada vale se o direito criminal for incerto, aplicado diferentemente em cada caso. Note-se que o princípio da certeza jurídica no mundo do direito criminal pressupõe não apenas o princípio da legalidade (o exclusivismo da lei criminal na criação do crime) mas, e principalmente, o da tipicidade, declaração do contido no art. $5^{\circ}$, inciso II, da Constituição Federal. ${ }^{5}$

Essa norma nada mais é do que a configuração jurídica do entendimento laico do crime, da capacidade de censura que o autor deve ter em relação ao seu cometimento; e capacidade de censura, vale dizer a capacidade de entender o caráter criminoso do fato e de determinar-se conforme esse entendimento, representa o entendimento de Del Vecchio, a consciência da necessidade da norma criminal. Quando o homem não consegue auferir, da norma, a consciência da sua necessidade, não há como se impor a capacidade de entender ou de determinar-se. Em outras palavras: o crime é uma conduta desviante da normalidade social; e quando a lei estabelecer como criminosa uma conduta que não seja desviante da normalidade social, não terá legitimidade, não conseguirá criar, no administrado, a consciência da sua necessidade e, portanto, a sua capacidade de entender e de auto-determinar-se.

O direito criminal, ouso dizer, está em coma; e prolongada. É preciso recuperá-1o, fazê-lo atual, interpenetrá-lo com princípios evolutivos de outros ramos jurídicos. Continuo achando que a lei criminal é exclusivista no estabelecer o crime e a contravenção, obedecidos determinados princípios e, principalmente, o conceito criminológico, pré-jurídico, de ilícito criminal: conduta desviante da normalidade social; mas entendo que, hoje, a descriminalização pode se dar com o costume, visto como a prática de uma conduta consciente da sua obrigação legal; em outros termos, no

5 "Ninguém será obrigado a fazer ou deixar de fazer alguma coisa senão em virtude de lei."

R. Fac. Direito, Curitiba, a.27, n.27, 1992/93. p.37-60 
direito criminal, a prática reiterada e constante de uma conduta com a consciência da sua atipicidade. Sem isso não há como se impor a capacidade de entendimento e de auto-determinação. O ilícito criminal é, por força do disposto no art. $5^{\circ}$, incisos II e XXXIX, da Constituição Federal, e art. $1^{\circ}$ do C. Penal, um ente jurídico, uma criação da lei - daí o caráter de exclusivismo da norma criminal, só esta determinando a existência do ilícito que lhe é próprio -; continua viva a constatação de Aliomar Baleeiro:

"o cidadão, no Brasil, é que está precisando de segurança. Nunca, penso eu, se matou tanto no Brasil - quer os criminosos, quer a polícia - do que agora". ${ }^{6}$

Há uma contradição entre o princípio autoritário, no dizer de Donicci, ${ }^{7}$ da lei e da ordem, e os princípios - direitos humanos individuais, indisponíveis pelo cidadão e sacrais para o Estado - da reserva legal e da tipicidade, este a relação próxima do direito criminal com a isonomia jurídica constitucional, e da presunção de inocência, que se reduz no reconhecimento de que o inquérito policial é um ato vinculado e, portanto, não pode representar uma devassa, como vinculado é o ato da denúncia. O outro lado dessa moeda é a obrigação de responsabilidade da cidadania, no sentido de não se poder fazer acusações

inócuas e desprovidas do mínimo fumus boni juris, até com abuso de poder, como lecionou Fragoso.

$\mathrm{O}$ até aqui exposto nada mais é do que a utilização do que o Eros Roberto Grau estabeleceu, em belíssima aula inaugural proferida na Faculdade de Direito da Universidade Federal do Paraná em 28 de fevereiro de 1994: a interpretação da norma criminal por princípios, dentre os quais avulta, entre outros, o da isonomia jurídica.

A visão correta é, pois, que a Constituição e o direito criminal existem em favor do administrado, regulamentando a atividade coercitiva, de força da administração pública, não o contrário, ainda que não se possa chegar ao exagero de Dorado Montero ao propor a visão do direito protetor dos criminosos; não, é a idéia de que a administração pública só possa atuar quando o administrado cometa uma das condutas típicas. Temos que sacudir

6 Pasquim $\mathrm{n}^{\circ} 455$, de 17 a 23 de março de 1979.

7 Criminalidade e estado de direito, Encontros com a Civilização Brasileira n ${ }^{\circ} 5$, p. $201 / 235$. 
um pouco o direito criminal. O criminalista ortodoxo pensa e age, sem confessar e até dizendo o contrário, como se coexistissem dois ordenamentos jurídicos: um ordenamento jurídico-criminal e outro ordenamento para as demais ciências jurídicas. O saudoso Munhoz Netto dizia que o direito criminal é um direito secundário para as autoridades porque, enquanto na elaboração de lei autorizatória da construção de uma pequena sala de aula, em uma pequena cidade do interior de um pequeno Estado do País, é necessário se apontar a fonte de recursos, para criar um crime basta criar o crime. E vimos, de 1964 para cá, quantos legisladores criminais surgiram, agora alguns açodadamente e por interesses eleitorais pessoais querendo a implantação da pena de morte no Brasil, quantas condutas passaram a ser criminalmente ilícitas sem que a sociedade as tenha desvalorado, quantas deixaram de ser ilícitas pelo costume, ainda que mantidas artificial e ilegalmente vivas, como esse jogo do bicho, como o adultério; é o exercício do que chamo de demagogia criminal (veja-se a demagógica lei chamada do colarinho branco, Lei $\mathrm{n}^{\circ} 7.492$, de 16 de junho de 1986 , modificada por ato do Banco Central do Brasil, sede alternativa do Congresso Nacional pela volúpia com que legisla ao arrepio dos mais comezinhos princípios do Direito). É importante que se diga que há um só ordenamento jurídico, a que também pertence o direito criminal, com os caracteres de ser unitário, completo e ausente de contradição. No Brasil, quando se trata de direito disponível, privado, acodem especialistas jurídicos de alto nível; quando se trata de direito criminal, qualquer concurso público de conhecimentos gerais habilita o aprovado a tratá-lo como se o conhecesse profundamente; e quantas denúncias ineptas vicejam por esses brasis afora!

O direito criminal, assim como vem sendo visto e praticado, mais do que um fator de criminalidade, como tenho insistentemente dito, é um crime em si.

\section{Uma visão de Estado}

A visão que se tem do Estado é a de que substitui o soberano absoluto, que tudo podia. O Estado de hoje, na visão terceiro-mundista, pode tudo; Estado de direito é o que obedece às suas leis, qualquer lei, pouco se importando com a capacidade de o administrado entendê-las, aceitá-las e sentir o seu comando.

R. Fac. Direito. Curitiba, a.27. n.27, 1992/93, p.37-60 
Ora, como diz Tércio Sampaio Ferraz, o Estado não é o outro mas, internamente, uma relação de poder entre as minorias e facções que o compõem (Nicos Poulantzas); quem necessita da lei, dizia o saudoso M. Seabra Fagundes, é a minoria; à maioria, a maioria basta. Portanto, Estado de direito é o que obedece às suas leis legítimas, aquelas que são criadas a partir da consciência coletiva do povo quanto à sua necessidade, aquelas que são capazes de ser entendidas e que, portanto, provocam a possibilidade de auto-determinação; já disse um jus-filósofo alemão que lei ilegítima é uma não-lei.

Nós vivemos duas realidades jurídicas ocidentais: uma, a do direito comum, de origem anglo-saxã; tome-se a Inglaterra, construída por vários povos, o anglo, o saxão, o celta, o povo antigo, o normando, o romano; como a maioria dos povos estava sempre dominada por algum outro, como até rei viking a Inglaterra teve, fez-se um pacto de poder em que ficou assentado que o povo dizia o direito material, já que ele sofreria a sua aplicação; então, o direito material comum foi estabelecido pelos usos e costumes do povo, aquilo que o povo entendeu como direito é o Direito material; sofisticadamente, no Direito continental-europeu, a consciência coletiva de necessidade da norma, do desvio da normalidade da conduta; mas como o poder dominante deveria aplicar esse direito material, o poder dominante dizia o direito processual. E estabeleceu-se o equilíbrio: o costume do povo fixou o direito material; o poder dominante estabeleceu, respeitados limites, o direito processual; o juiz era pago pelo povo, a fim de impedir que as suas necessidades, satisfeitas pelo soberano, pudessem fazer, dele, uma longa manus do poder. Sintam que as constituições americana (escrita, positiva) e a inglesa (consuetudinária) preocupam-se, no tocante às liberdades públicas, com o direito processual, não porque, instrumental, seja superior ao direito material, mas porque é um direito do poder, não um direito do povo, e a Constituição existe exatamente para limitar os poderes do poder. Então se diz que ninguém será considerado culpado antes de condenação definitiva, ninguém será preso sem ordem judicial, toda pessoa tem direito de se calar, toda pessoa acusada tem direito a um advogado e assim por diante.

Nós temos um direito diferente. No nosso caso, no caso do ordenamento jurídico oriundo das civilizações européias continentais, ocidentais, substituiu-se a figura do soberano absoluto pelo Estado. O soberano absoluto congregava os poderes executivo, legislativo e judiciário; por cansaço ou para obter recursos financeiros, distribuía ou vendia parte desses poderes 
a outras pessoas ou grupos. E nós substituimos a pessoa do soberano absoluto pelo Estado e passamos, então, a acreditar que o direito é o que o Estado diz, Estado de Direito é o que obedece às suas leis; esquecemos que o Estado pode sofrer distorções e transformar-se em autoritário, em ditatorial e impor leis que não sejam oriundas da consciência coletiva do povo quanto à sua necessidade, leis que não tipificam condutas desviantes, leis que não vão, nem podem, ser obedecidas; sirva de exemplo a grande diferença que existe entre o crime fiscal nos Estados Unidos e nos países latinos. Malinverni já disse que sonegar tributos é, na Itália, um esporte nacional; e é um esporte nacional aqui também. Talvez seja, hoje, em uma visão de mundo, um esporte olímpico, na medida em que, para ser olímpico, se exige que cinquenta países o pratiquem constantemente; isso porque, repita-se à exaustão, não adentrou a consciência coletiva da sua necessidade porque não tipificam condutas desviantes nos países latinos, que sofrem a imposição da lei estatal, enquanto nos países anglo-saxões, em que a criação do direito material decorre do próprio povo, essa consciência existe. De qualquer forma não se pode confundir planejamento tributário com sonegação, como vem ocorrendo, lamentavelmente, neste nosso País.

Nesse exemplo extremo eu pretendi fixar que não se pode criar condutas criminalmente ilícitas quando estas, na consciência do povo, não representam um desvio da normalidade social. E essa normalidade social deve ser vista como um corte vertical de todos os estamentos, jamais a imposição da vontade de uma maioria ocasional sobre as minorias ocasionais. Nesse passo o direito legislado e o direito comum se aproximam enquanto fontes; apenas a elaboração das leis sofrem processos diferentes. A formação do direito é a mesma - a consciência coletiva do povo da necessidade da norma -; a partir daí, nos países anglo-saxões, cria-se o precedente judiciário, enquanto nos países de legislações positivas o Congresso Nacional elabora a lei, não a que os seus integrantes querem, mas a que o País quer, entendida como necessária e contendo uma conduta desviante da normalidade social.

O legislador tem limites. A administração pública se submete ao princípio da legalidade, conforme dispõe a Constituição Federal no seu art. 37. E esse princípio - que por ser princípio é mais importante que a norma em si, segundo ensinamento de Gordillo, pois que orienta e impõe a sua correta interpretação, dentro do conceito de mens legis -implica em que a administração, ao contrário do que erradamente pensam os eventuais ou

R. Fac. Direito. Curitiba, a.27. n.27. 1992/93. p.37-60 
atuais donos do poder, só pode fazer aquilo que a lei expressamente a autoriza, enquanto o administrado pode fazer tudo que a lei expressamente não o proíba; é o que ensina o excelente C. A. Bandeira de Mello.

Com base no que expus, pode-se fazer uma releitura da proibição da analogia no direito criminal: não há analogia porque, onde não há tipo, há uma lei autorizando criminalmente a conduta. E aplicar a analogia é desobedecer a lei. Isso porque a lacuna na parte especial, na parte da tipificação das condutas, é intencional. Nesse aspecto vale o alerta de López-rey, ao tratar do ensino da criminologia moderna, que deve ser, no seu entendimento, cometido a

"... um novo tipo de criminólogo. Para esse fim, o currículo criminológico deve incluir a ciência política, a história, a teoria e a prática dos direitos humanos e a filosofia." 8

De outro lado não se pode perder de vista a crise que se imputa, hoje, ao direito criminal. Necessário dizer-se que a evolução histórico-doutrinal dessa disciplina é de tal forma dinâmica que chega a levar os seus estudiosos, não raras vezes, à perplexidade; desde uma concepção estatizante, na qual o direito punitivo servia mais ao Príncipe do que ao Estado - protegendo preconceitos religiosos e sentimentos de casta -, passando por uma fase de confusão entre moral e direito (o mínimo ético, no dizer de Manzini), até o atual enfoque de representar o limite das liberdades e das garantias individuais, dentro de um conceito material de Estado de direito liberal (apenas o liberalismo econômico, jamais o político, está superado), muita coisa mudou. De qualquer forma, por um erro filosófico, sempre se cometeu ao direito criminal a responsabilidade quase única de combater as condutas desviantes; a cada vez que a delinquência recrudesce, intensificam-se as acusações de fracasso do direito criminal e criam-se novas condutas típicas, desarrazoadas e sem qualquer fundamento na consciência popular. Hoje vive-se uma época em que o aperfeiçoamento das formas criminosas sutis, galgando as elites sócio-econômicas, e o concomitante aumento da criminalidade violenta atraem a atenção dos dirigentes e dos estudiosos e recaem sobre o princípio constitucional da isonomia jurídica e sobre o direito criminal como afirmações da sua falência. Tomem-se como exemplo as recentes entrevistas de autoridades governamentais federais a respeito da legislação e da Justiça criminais; tomem-se como exemplos as manifestações apressadas, ainda que com tom de definitivas, acerca do jogo do bicho. A responsabilização do direito criminal é, porém, absolutamente in-

8 Manifesto Criminológico, Revista de Direito Penal n 24, p. 16. 
válida; não se pode impor o potencial conhecimento do ilícito a quem não recebe o comando da norma porque a conduta que tipifica não é desviante da normalidade social; dentro de um enfoque de tipo pluridimensional, falta o tipo subjetivo nesses casos e, consequentemente a conduta é atípica (erro de proibição, totalmente escusável). Na verdade, o fim primordial do direito criminal é exatamente - enquanto subordinada a imposição da pena à culpa do autor - retribuição e ou castigo, somente possível quando a conduta seja evidentemente típica e censurável. Outro não é o entendimentode Lopezrey:

"Enquanto subsistam os sistemas de justiça penal, sua ratio essendi e a do direito criminal não é a correção, a ressocialização ou a reabilitação do delinquente, mas, sim, a justiça social." 9

Volta a demagogia criminal, desta vez a reclamar novos figuras típicas apenas porque a tecnologia evoluiu; reclama-se da necessidade de se criarem figuras típicas que englobem o computador; mas este não é apenas um instrumento para a prática, por exemplo, do estelionato? Acaso precisa-se modificar o art. 121 para englobar os homicídios praticados com armas mo-dernas, laser, por exemplo? A responsabilidade de manter atualizada a norma criminal é dos doutrinadores e do Poder Judiciário. A isso chamo tirar o direito criminal do coma: desengessá-lo de decisões desatualizadas, perder a preguiça e reler o direito criminal sob o enfoque da evolução tecnológica e social.

O Brasil tem muito sobre o que pensar.

Vale, por fim, referir à importação, pelo processo criminal do civil, do conceito do direito abstrato de agir (alguns processualistas criminais já reagem a essa situação caudatária; vale citar o Jacinto Coutinho); isto é, tem-se ação ainda quando não se tenha o direito material. Ora, no processo criminal deve viger, como corolário da isonomia jurídica, o princípio da presunção de inocência, pois que o processo criminal, já se disse, começa punindo para saber se se deve punir. Portanto, a ação penal deve se conter dentro do conceito de direito concreto, sob pena de o agente do parquet estar cometendo abuso de autoridade, quando a sua denúncia não se embasa em sólidas provas materiais e indiciação de autoria. Volta-se, sempre, ao ponto de partida: a irresponsabilidade de acusações temerárias, apressadas, antes da produção de qualquer prova, entendida no sentido de ser dialeticamente

9 Manifesto Criminológico, Revista de Direito Penal n 26, p. 16.

R. Fac. Direito. Curitiba, a.27. n.27. 1992/93, p.37-60 
contraditada e disponível (a cross examination americana), vale dizer nãosecreta: o direito abstrato de ação em marcha batida para a falência da legislação criminal.

Por isso, ao encerrar estas linhas, permito-me fazê-lo parafraseando o alerta de Lopez-rey:

$"$ "... se o direito criminal deseja sobreviver, deve-se dar conta de que a criminalidade convencional não é mais do que um aspecto do fenômeno sócio-político da criminalidade, que os países em desenvolvimento devem ser estimulados a desenvolver seus próprios enfoques, ao invés de imitar os que existem em países muito diferentes em que o estudo da criminalidade não convencional, exige um enfoque que o direito criminal contemporâneo não pode dar." 10 